\title{
Comparative Observation of the Pancreatic A and B Cells by the Enzyme Antibody Method: Light Microscopic Findings in Dog and Mouse Tissue
}

\author{
Toshimitsu SUZUKI*, SeIKI ITO** and Hideo SASAKI** \\ Department of Pathology* and the 1st Department \\ of Internal Medicine**, Niigata University School \\ of Medicine, Niigata City, Niigata 951
}

\begin{abstract}
Synopsis
$A$ and $B$ cells of pancreatic islets of the dog and mouse were stained by the enzyme-antibody method. A cells, in general, were small in number, particularly in the mouse, and distributed at the peripheral zone of the islet. Furthermore, A cells were located very close to the intrainsular capillary. On the other hand, B cells occupied dominantly the islet and mainly existed in its central area, especially in the mouse and not adjacent to the intrainsular capillary.

A positively reacting cell with anti-insulin antibody was also found in the uncinate process of the dog pancreas, while there was no positively reacting cell with anti-glucagon antibody. This fact, as there were only two kinds of islet cells, B cell and the third cell of the islet (named D cell) in the uncinate process, showed that the $\mathrm{D}$ cell had neither glucagon nor glucagon-like immunoreactivity.
\end{abstract}

Since the enzyme-antibody method has been developed by Nakane in 1966, it is confirmed to be the most reliable method to detect the localization of tissue antigen. This method has revealed immunohistopathologically that it is as specific as an immunofluorescent method. It is noted that this is available to electronmicroscopic study as well as light microscopic study. Furthermore, the microscopic specimen of this method stays almost permanently useful, and may be observed with an ordinary light microscope without any special equipment. This method is widely applied to immunohistochemical study in the same way as in the immunofluorescent method. For example, the identification of individual hormone producing cell of the anterior pituitary gland (Nakane et al., 1967), detection of antinuclear antibody (Murohashi et al.,
1970), and investigation of glomerular changes in the various renal diseases (Murohashi et al., 1971) by this method were reported. And it was also applied as an immunoelectronmicroscopic method to the detection of virus antigen (Hoshino et al., 1971), localization of intracellular antigen (Leduc et al., 1969; Kawarai et al., 1971) and production site of myelomagloblin (Suzuki et al., 1969). Comparing this with the ferritin antibody method, the enzymeantibody method has the advantage of more excellent penetrability into the cell, because the molecular size of enzyme-labeled antibody is smaller than that of the ferritinlabeled. This experiment was designed to confirm the presence and distribution of the insulin and glucagon secreting cells in the pancreatic islets of several animals using the enzyme-antibody method. 


\section{Materials and Methods}

Anti-insulin antibodies were produced in a guinea pig by beef insulin and anti-glucagon antibodies were raised in rabbit by the previously reported method (Ito et al., 1974). Anti-rabbit IgG antiserum was produced in the guinea pig by immunization against purified rabbit IgG (Seikagaku Chemical Co.). Coupling reaction of horseradish peroxidase with antiinsulin antibody of anti-rabbit IgG antibody was performed by the single step method using glutaraldehyde as a bifunctional reagent (Avrameas, 1969). Detection of specific cells was performed by direct method for insulin and by indirect method for glucagon. Antibodies were purified by salting out with $33 \%$ ammonium sulfate solution and dialyzed against $0.1 \mathrm{M}$ phosphate buffered saline (PBS), pH 7.4. The final concentration of the antibodies was $25 \mathrm{mg} / \mathrm{ml}$. Horseraddish peroxidase (R.Z. 1.4 Sigma), $50 \mathrm{ml}$, was dissolved in $2 \mathrm{ml}$ of the antibody solution was added to the enzyme-antibody mixture dropwise with gentle agitation at room temperature for 2 hours. The reaction was stopped by dialysis against the same buffer. The coupled mixture was purified by gel filtration through a column of Sephadex G200, $2.5 \times$ $40 \mathrm{~cm}$ in length, with $0.1 \mathrm{M}$ PBS. Each of $3 \mathrm{ml}$ of the elution was collected and antibody titer was de-

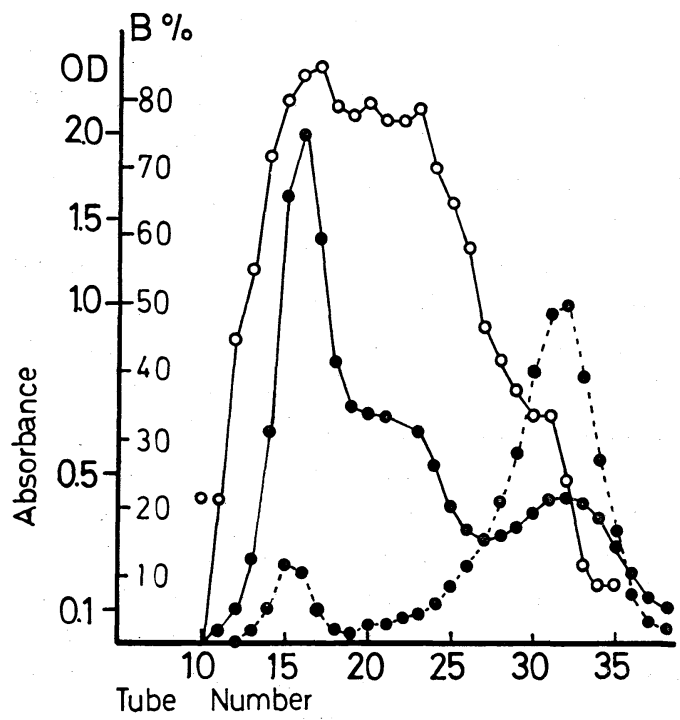

Fig. 1. Fractionation patterns of peroxidase labeled $\gamma$-grobulin. ._. $280 \mathrm{~m} \mu$ absorption, .._.. $403 \mathrm{~m} \mu$ absorption. ○— binding capacity (B) of insulin antibody. Column; Sephadex G-200, Height $45 \mathrm{~cm}$, volume per fraction $3 \mathrm{ml}$. termined by radioimmunoassay. Antibody and peroxidase protein concentration were determined by O.D. at $280 \mathrm{~m} \mu$ and O.D. at $403 \mathrm{~m} \mu$ respectively. As shown in Fig. 1, there were three protein peaks plotted in elution pattern of Sephadex G200. The activity of enzyme-labeled-antibody, was found from the tube No. 16 to 25 (Fig. 1). Therefore these fraction tubes were pooled and concentrated 10 times by polyethylene glycol (M.W. 20,000) and used for further experiment.

Pancreatic tissue was obtained from a onemonth-old puppy and the $\mathrm{C} 3 \mathrm{H}$ mouse. Each specimen was diced into one square centimenter with 3 $\mathrm{mm}$ thickness and fixed by three different fixatives$2 \%$ carbodiimide (0.1 M PB, pH 7.4) for 2-6 hours at $4^{\circ} \mathrm{C}$, by mixture of $2 \%$ paraformaldehyde and $1 \%$ glutaraldehyde for 2 hours at $4^{\circ} \mathrm{C}$ and by $95 \%$ alcohol at $-20^{\circ} \mathrm{C}$ for 2 hours. The specimens fixed by the former two methods were washed with Holt's solution overnight. Afterwards all of the fixed pancreatic blocks were dehydrated through the gradient cold ethanol series, soaked into xylol and embedded in paraffin. To examined the $B$ cell of pancreatic islets, the preparation was reacted with peroxidase coupled insulin antibody at $4^{\circ} \mathrm{C}$ for 2 hours or overnight. For the A cell, the specimen was stained with glucagon antibody at $4^{\circ} \mathrm{C}$ overnight. After washing with staining buffer, the slice was reacted with enzyme-labeled anti-rabbit IgG antibody at $4^{\circ} \mathrm{C}$ for 3-4 hours. And then each of stained slides was immersed in Graham-Karnovsky's solution, or in 4-Cl-1-naphthol (Tokyo Kasei) solution by the method of Nakane. Some of them, after washing, were layered on by $1 \%$ osmic acid to enhance the contrast of reaction product and some were counterstained by $0.5 \%$ methyl-green. And then they were mounted by Eukitt (mounting reagent, P. Kindler, Germany). But slides immersed in 4-Cl-1-naphthol solution were mounted by glycerine gelatin, being devoid of dehydration by alcohol as the reaction product, violet in color, was easily soluble out in alcohol. Several control stainings were performed as follows; staining by nonconjugated primary antibody only (for B cell) and conjugated secondary antibody only (for A cell), and also blocking to specific antibody by corresponding antigens.

Immunofluorescent staining for pancreatic $A$ and B cells was done by the usual method for reference. Light microscopic observation of aldehyde fuchsin stained specimens after modified Bouin's fixation was made for the comparison with the result of enzymeantibody method. 


\section{Results}

All of the specimens prepared by different fixatives showed almost similar results. But the maintenance of tissue architecture was best when fixed by paraformaldehydeglutaraldehyde mixture and shrunk most by ethanol fixation.

The cells reacting positively with antiinsulin antibody of the dog pancreas were mainly distributed in the central zone of the islet in group and their cytoplasmas were stained diffusely with partial granular appearance except for the nuclei (Fig. 2). These cells were not adjacent to an intrainsular capillary but intercalated by several layers of non-positively-reacting cells between the capillay. On the other hand, the cells positively stained by antiglucagon antibody were mostly found in the peripheral zone of the islet as a single cell layer or scattered in small group (Fig. 3). The glucagon positive cells, however, were rarely observed in small groups of three or four cells in number in the central area of the islet.

In this occasion the glucagon positive cells had close contact with the intrainsular capillary. The cytoplasm of the glucagon positive cell was also stained diffusely but more granular than that of the insulin positive cell. The population of the glucagon positive cells was about one-third or one-fourth of the insulin positive cells.

The islet of the uncinate process of the dog pancreas, most of them small and irregular-shaped, was positively stained only by the anti-insulin antibody (Fig. 4). The anti-glucagon antibody failed to react positively with the insular cells of the uncinate process (Fig. 5).

The pancreatic islet of the mouse showed a more definite difference in the mode of distribution between the insulin and glucagon positive cells. The former about ninety percent of the insular cells were located in the central region of the islet (Fig. 6). On the other hand, the latter, small in number, about five or ten percent of the insular cells, were found in a limited way in the peripheral zone of the islet in an incomplete circular arrangement of a single cellular layer (Fig. 7).

The mode of the distribution of A cells and B cells observed by aldehyde fuchsin stain bore a very close resemblance to that by the enzyme antibody method (Fig. 8). And the immunofluorescent stain of A cells naturally showed a similar result (Fig. 9). Control studies did not show any positive cells.

\section{Discussion}

Both preparations, i. e. by the enzymeantibody method and by the immunofluorescent staining showed the same findings. of positively reacting cell population and mode of distribution. Aldehyde fuchsin stain also revealed a similar result to that of the enzyme-antibody method. The enzyme antibody method, however, is more specific to detect the hormone secreting or laden cell than the ordinary histochemical staining method. Moreover, the specificity of this method is confirmed easily by the several combinations of control studies, comparing the histochemical method. Furthermore, as the aldehyde fuchsin stain was regarded not to stain insulin and/or glucagon itself (Fujita, 1973), it may be in some instances impossible to distinguish exactly $\mathrm{A}$ (glucagon secreting) and $B$ (insulin secreting) cells from each other or from another (D cell) in the pancreatic islet by this method. Therefore, the enzyme-antibody method is a more suitable technique to examine precise localization and mode of distribution of the insular cells. The real merit of this method will be exhibited enough in the identification of the hormone secreting or laden cells not limited to the pancreatic 

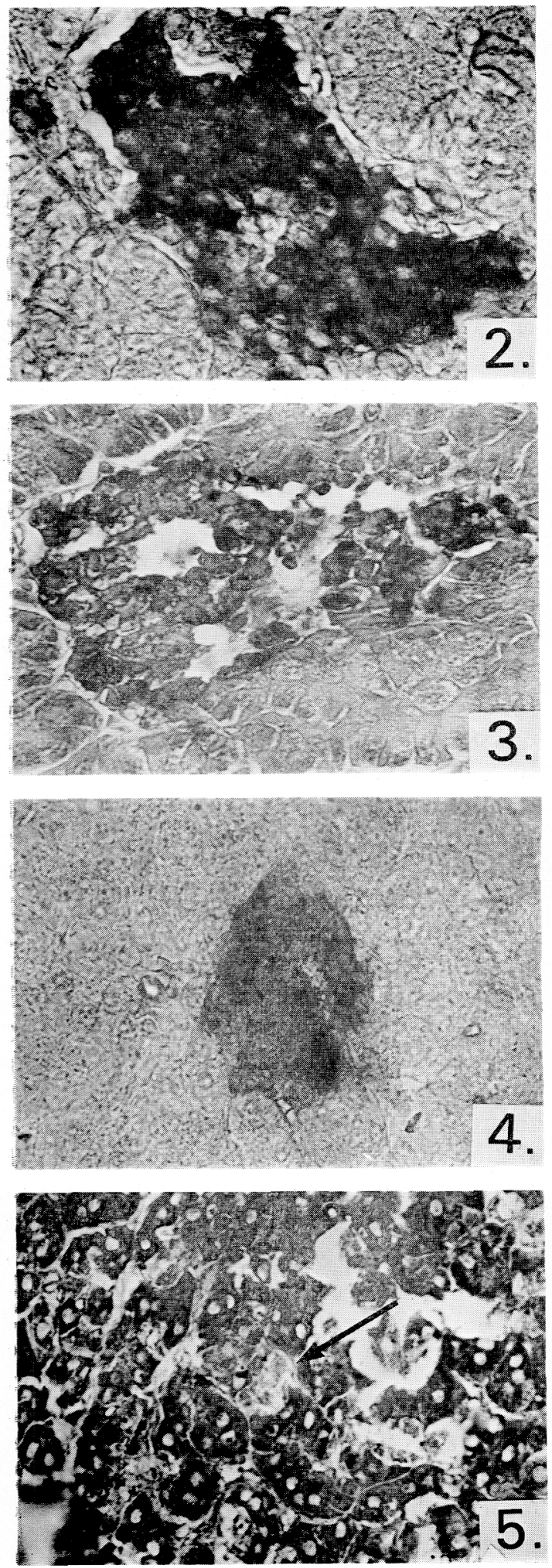
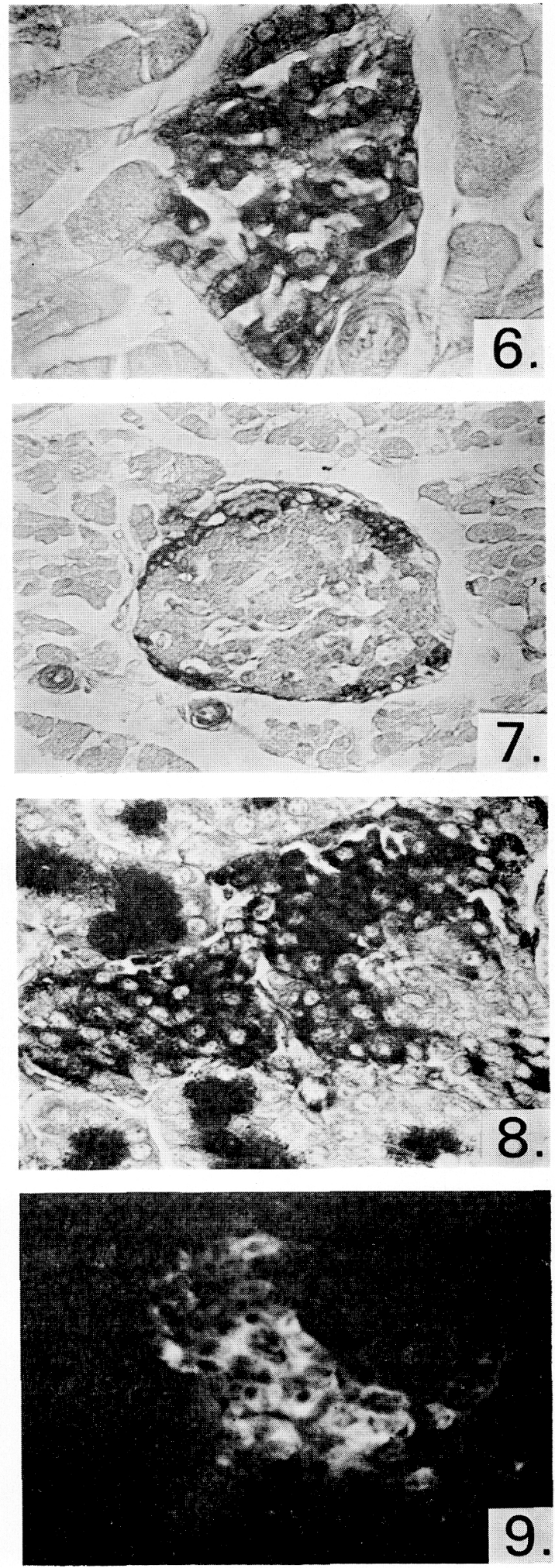
islet but also to other endocrine glands. The mode of distribution of A and B cells was variable from animal to animal, as it has been recognized by the aldehyd fuchsin staining (Fujita, 1973).

The A cells, however, in general were small in number and had a tendency to distribute at the periphery of the islet. The A cells of the dog and mouse pancreatic islets were in close location at the intrainsular capillary. On the other hand, the B cells, many in number, located at the central area of the pancreatic islet in group and were not adjacent to the insular capillary. This different localization between the $\mathrm{A}$ and $\mathrm{B}$ cells in the islet may show the interaction of A and B cells, that glucagon might stimulate insulin secretion via the insular capillary flow. Fujita et al. described the insuloacinar portal system in which the blood of the islet flows from A cell group to B cell group and then to the exocrine glands (Fujita, 1973). The islets of the uncinate process of the dog pancreas, where there was no A cell but where B and D cell existed, has not any positive cell reaction with anti-glucagon antibody, while $B$ cells were detected by the anti-insulin antibody. This fact suggested that D cell had neither glucagon nor glucagon-like immunoreactive substance.

This enzyme-antibody method has several advantages compared with the immunofluorescent staining. However, the effective and efficient conjugation between the enzyme and antibody was not so easy and the conjugation rate was relatively low. Therefore, highly sensitive antibodies must be obtained in order to keep enough activity after the conjugation procedure. The merit of this method above all is its availablility to the immunoelectronmicroscopic study. A dilemma, however, between the maintenance of electronmicroscopic fine architecture and the preservation of protein or polypeptide antigenicity stood in front of the immunoelectronmicroscopic application. But recently Nakane et al. have developed a new conjugation method (Nakane et al., 1974) and newly modified fixation for electronmicroscopy (McLean et al., 1974). So this method may be more widely available with more ease in both light and electronmicroscopic immunohistopathology. And more precise morphological changes in normal or diseased state of the pancreatic islet cells will be obtained.

\section{References}

Avrameas, S. (1969). Immunochemistry 6, 43.

Fujita, T., N. Hasegawa, Y. Koga, Y. Kameda and K. Takashi (1968). Arch. Histol. Japon. 29, 313.

Fujita, T., in Kuzutani, N. (ed.), Internal Medicine, Series No. 3, "Tonyobyo no. Subete", Nankodo, Tokyo, 1971, p. 43. (in Japanese).

Fujita, T. Arch. Histol. Japon. (1973). $35,161$.

Hoshino, M. and K. Maeno (1971). J. Electron-microscopy 20, 49.

Ito, S. and H. Sasaki (1974). Folia Endocrinol. Japon. 50, 245 (in Japanese).

Fig. 2. Dog pancreas stained with anti-insulin antibody. $(\times 440)$

Fig. 3. Dog pancreas stained with anti-glucagon antibody. $(\times 440)$

Fig. 4. Uncinate process stained with anti-insulin antibody. $(\times 440)$

Fig. 5. Uncinate process stained with anti-glucagon antibody. $(\times 440)$

Fig. 6. Mouse pancreas stained with anti-insulin antibody. $(\times 440)$

Fig. 7. Mouse pancreas stained with anti-glucagon antibody. $(\times 210)$

Fig. 8. Dog pancreas, aldehyde fuchsin stain. B cells stained dark blackish and A cells light grey in this figure. $(\times 440)$

Fig. 9. Dog pancreas, immunofluorescent stain by anti-glucagon antibody. $(\times 400)$ 
Leduc, E. H., G.B. Scott and S. Avrameas Allergy 20, 353 (in Japanese). (1969). J. Histochem. Cytochem. 17, 211. Nakane, P. K. and G. B. Pierece, Jr. (1966).

Kawarai, Y. and P. K. Nakane (1970). Ibid. 18, 161. J. Histochem. Cytochem. 14, 929.

McLean, I. W. and P. K. Nakae (1974). Ibid. 22, 1077.

Nakane, P. K. and G. B. Pierece, Jr. (1967). J. Cell. Biol. 33, 307.

Murohashi, K., Y. Kinoshita and K. Kojima Nakane, P. K. and A. Kawaoi (1974). J. Histochem. Cytochem. 22, 1084. (1970). Clin. Immunol. 2, 385 (in Japanese).

Suzuki, I. and M. Takahashi. (1969). Experientia 25, 1307.

Murohashi, K. and Y. Kinoshita (1971). 